\title{
Situated Peer Coaching and Unfolding Cases in the Fundamentals Skills Laboratory
}

Deborah O. Himes

deborah-himes@byu.edu

Patricia K. Ravert

Follow this and additional works at: https://scholarsarchive.byu.edu/facpub

Part of the Nursing Commons

\section{Original Publication Citation}

Himes, D. O. \& Ravert, P. K. (212) Situated peer coaching and unfolding cases in the

Fundamentals Skills Laboratory. International Journal of Nursing Education Scholarship, 9(1).

http://dx.doi.org/1.1515/1548-923X.2335. http://www.degruyter.com/view/j/

ijnes.212.9.issue-1/1548-923X.2335/1548-923X.2335.xml

\section{BYU ScholarsArchive Citation}

Himes, Deborah O. and Ravert, Patricia K., "Situated Peer Coaching and Unfolding Cases in the Fundamentals Skills Laboratory" (2012). Faculty Publications. 72.

https://scholarsarchive.byu.edu/facpub/72

This Peer-Reviewed Article is brought to you for free and open access by BYU ScholarsArchive. It has been accepted for inclusion in Faculty Publications by an authorized administrator of BYU ScholarsArchive. For more information, please contact ellen_amatangelo@byu.edu. 


\title{
International Journal of Nursing Education Scholarship
}

Volume 9, Issue 1

Article 18

\section{Situated Peer Coaching and Unfolding Cases in the Fundamentals Skills Laboratory}

\author{
Deborah O. Himes* $\quad$ Patricia K. Ravert ${ }^{\dagger}$
}

*Brigham Young University, deborah-himes@byu.edu

†Brigham Young University, patricia_ravert@ byu.edu DOI: $10.1515 / 1548-923 X .2335$

Copyright (c)2012 De Gruyter. All rights reserved. 


\title{
Situated Peer Coaching and Unfolding Cases in the Fundamentals Skills Laboratory*
}

\author{
Deborah O. Himes and Patricia K. Ravert
}

\begin{abstract}
Using unfolding case studies and situated peer coaching for the Fundamentals Skills Laboratory provides students with individualized feedback and creates a realistic clinical learning experience. A quasi-experimental design with pre- and post-intervention data was used to evaluate changes in student ratings of the course. An instrument was used to examine students' selfratings and student comments about each lab. We found that students' ratings of the lab remained high with the new method and self-evaluations of their performance were higher as the semester progressed. Students appreciated the personalized feedback associated with peer coaching and demonstrated strong motivation and self-regulation in learning. By participating in unfolding case studies with situated peer coaching, students focus on safety issues, practice collaborative communication, and critical thinking in addition to performing psychomotor skills.
\end{abstract}

KEYWORDS: unfolding case studies, situated peer coaching, simulation evaluation, situated learning, peer feedback

${ }^{*}$ Brigham Young University provided funding through Muriel Thole Teaching and Learning Fellowship. 
Novice nursing students begin early to develop the knowledge, skills, attitudes, critical thinking, and clinical judgment patterns they will take with them into their nursing careers. The influential work Educating Nurses: A Call for Radical Transformation by Benner, Sutphen, Leonard, and Day (2010)details the need for students to experience situated cognition in their education, that is, the opportunity to think through"particular clinical situations"(p.30) to develop their capacities as professional nurses. Benner et al. further assert that a key element of situated learning is an environment where educators coach students through particular experiences. They identify "situated coaching as signature pedagogy in nursing education" (p.30).Oermann and Gaberson(2009)assert that frequent, prompt, and personalized feedback is one of the most important variables that impacts learning. The Institute of Medicine (IOM) report, The Future of Nursing: Focus on Education(2010), declares that in nursing education we must "move from task-based proficiencies to higher-level competencies that provide a foundation for care management knowledge and decision-making skills under a variety of clinical situations and care settings(p. 2). This paper describes the impact of an innovative approach to learning in the Fundamentals of Nursing Skills Laboratory that applies the teaching strategies called for by these influential voices. We measure impact by comparing quantitative and qualitative student ratings of the course pre- and post-implementation. We also examine students' self-evaluation of knowledge, skills, and attitudes over time.

Our approach to teaching the Fundamentals Skills Laboratory utilizes the principles of situated cognition and situated coaching advocated by Benner et al.(2010) with a slight variation. They describe situated coaching as instructors coaching students in clinical and classroom situations. With our teaching method, same-level peers coach one another weekly in a laboratory setting using unfolding case studies; we have termed this approach "situated peer coaching". While students practice psychomotor skills, they also make critical assessments and decisions that impact patient care during the scenario. Thus, we are addressing competencies beyond psychomotor skills as called for by the IOM (2010).Through laboratory scenarios, students are provided opportunities to practice competencies outlined by the Quality and Safety Education for Nurses project (QSEN, n.d.), including patient-centered care, safety, and teamwork and collaboration.

During our Fundamentals Skills Laboratory, instructors provide initial demonstration and direction about a skill, then students pair up for the scenarios. One student acts as a coach and the other as the nurse. Peer coaches follow a detailed script to advance a scenario through role-play. Peer coaches provide realtime personalized feedback described by Oerman \& Gaberson(2009) as being critical to learning. The script provides the peer coaches with probing questions to 
ask their partner as the case unfolds such as, "What is the potential risk in this situation?" Scripts describe what actions and responses to watch for from the laboratory partner. The pair works through a debriefing discussion at the end. Instructors monitor student pairs and provide additional insight and feedback. After one scenario is completed, the students switch roles and the next unfolding scenario begins. Four patient stories unfold over the 14-week semester.

\section{BACKGROUND \& LITERATURE REVIEW}

\section{Scripted Unfolding Case Studies (Laboratory Scenarios)}

Case studies have long been used in nursing education to help students develop clinical judgment. Case studies are typically written descriptions of realistic clinical events that present students with a problem to analyze and solve. They might document an actual situation that occurred or involve an imagined scenario. To make the experience realistic, an unfolding case study model is used. In unfolding case studies, not all information is presented up front, which helps students develop clinical reasoning and promotes experiential learning. Unfolding case studies are similar to actual nursing practice, where nurses must begin care before all information is known and the physical, mental, and emotional status of the patient changes over time (Azzarello \& Wood, 2006). Case studies are used in both nursing classrooms (Day, 2011) and in simulation laboratories(Bamber et al., 2010; Reese, 2011).Scripting adds another layer to the technique; scripted unfolding case studies require participants to converse with one another as they play their respective roles (Page, Kowlowitz, \& Alden, 2010).

\section{Peer Learning}

Peer learning is the broad category under which peer coaching falls. The idea of peers helping one another learn has been around for many years. In the literature, this concept has been referred to as cooperative learning, peer teaching, peer tutoring, peer assisted learning, peer mentored learning, and peer coaching, to name a few (Ladyshewsky, 2000). Although definitions vary, all peer learning involves either students or professionals (who are not formal teachers) working together to meet specific learning objectives by providing evaluation and feedback.

Peer learning improves student outcomes and cost outcomes. Some of the benefits of peer learning include the opportunity to provide immediate, individual feedback and guidance through formative assessment (Iwasiw \& Goldenberg, 1993; Liu \& Carless, 2006; Wilkins, Shin, \& Ainsworth, 2009), increased 
Himes and Ravert: Situated Peer Coaching and Unfolding Cases in Fundamental Lab

motivation, and improved self-regulation in learning (Asghar, 2010).Peer learning decreases anxiety and increases student self-efficacy (Harlow, Burkholder, \& Morrow, 2006; Ladyshewsky, 2010; Sprengel \& Job, 2004). In the clinical setting, students who participate in peer learning report enhanced learning as well as a feeling of emotional and physical support during the experience (Chojecki et al., 2010). Ultimately, peer learning can improve knowledge. Because peers communicate with one another at a similar level, they can explain complex topics more effectively to one another and enhance their own learning through the process of teaching (Evans \& Cuffe, 2009). Topping (2005) described peer learning as a cost-effective learning strategy that increases academic achievement, social and communication skills, students' regard for the subject matter, and student self-esteem. Hunt \& Ellison (2010) noted that peer mentoring enhances student self-confidence, improves understanding of professional values, and maintains student knowledge and skill development while conserving faculty time.

\section{Peer Learning in Fundamentalsof Nursing Skills Laboratory}

Peer learning in the forms of peer teaching and peer leadership have a positive impact on student outcomes in the Fundamentals of Nursing Skills Laboratory. Bensfield, Solari-Twadell, and Sommer (2008) describe a method of teaching that involves junior level students acting as peer leaders for sophomores enrolled in the course. The peer leaders receive credit for these activities as part of a leadership course. The investigators report benefits for all students, including the peer leaders. Hunt and Ellison (2010)describe a similar situation where peer mentors are trained as part of a class. They report no significant differences in knowledge gained (as measured by quiz scores) between peer-led laboratories and mentor-led laboratories. Owens and Walden (2001) describe the use of peer instruction in a Nursing Fundamentals Skills Laboratory where senior nursing students were hired to help mentor students during their laboratory practice time. They found increased confidence and decreased anxiety in novice students when peer instructors were utilized. Goldsmith, Stewart, and Ferguson (2006) describe a peer learning partnership where third-year nursing students assist first-year students in the Fundamentals Skills Laboratory. They report that students feel comfortable giving and receiving formative feedback and that both sets of students improved in comfort with the skills. Godson and Wilson (2007) report on a project where third-year students were taught how to teach first-year students the skill of medication administration. In this study the benefits of mentorship in the Fundamentals Skills Laboratory transferred to the clinical setting; clinical mentors in practice reported students who received peer instruction were more confident and better prepared for their clinical placements. 
International Journal of Nursing Education Scholarship, Vol. 9 [2012], Iss. 1, Art. 18

\section{Peer Coaching}

Peer coaching, in contrast to peer teaching or mentoring, describes samelevel students or practitioners assisting one another to meet learning objectives. The coaching relationship may be reciprocal or unidirectional but it is not hierarchical. Peer coaching takes place in an educational or clinical setting where peers offer formative feedback that is not associated with a grade (Ladyshewsky, 2010).

Peer coaching has been described in nursing literature relating to the orientation of newly graduated nurses as well as professional development (Poe, Abbott, \& Pronovost, 2011; Waddell \& Dunn, 2005; Zadvinskis, Glasgow, \& Salsbury, 2011).Although nursing education offers a great deal of literature discussing other types of peer learning, we have not been able to locate literature that describes peer coaching or situated peer coaching where same-level peers coach one another in the Fundamentals Skills Laboratory. Secomb (2008) completed a systematic review of the literature related to the effects of all types of peer learning in nursing clinical and laboratory education. None of the articles reviewed involved same-level students providing peer coaching.

\section{Reciprocal Peer Coaching}

Reciprocal peer coaching is a method of peer learning where students take turns coaching one another; all students have the opportunity to coach and to be coached. Ashgar (2010) describes reciprocal peer coaching in physical therapy education and notes that reciprocal peer coaching has some distinctive advantages over peer teaching, or peer leadership. Very often in peer teaching the peers are required to evaluate one another in some kind of summative fashion where mistakes result in a grade penalty. Reciprocal peer coaching involves collaborative, formative assessment with the goal of further learning. This helps students assume responsibility for their own actions and learning as they reflect on their own performance as well as that of others. These are critical skills in healthcare, where self-regulation and lifelong learning are highly valued.

\section{Situated Peer Coaching}

Benner et al. (2010) call for nurse educators to teach in the clinical setting using a technique called situated coaching. They promote bringing experiential clinical learning and situated coaching into the classroom through case studies noting, "continued situated coaching is required for the student to grasp the changing relevance, and demands, resources, and constraints in a particular situation and therefore it entails developing a sense of salience"(2010, p. 83). 
Himes and Ravert: Situated Peer Coaching and Unfolding Cases in Fundamental Lab

\section{Learning Framework - Situated Cognition}

Situated peer coaching mirrors the principles and components of situated cognition, a learning framework proposed by Paige and Daley (2009)that supports and guides high fidelity simulation. They note:

To situate learning means to create conditions in which learners will experience the complexity and ambiguity of learning in the real world. Cooperative and participative teaching methods are used. Subject matter emerges from the cures provided by the environments and the dialogue within the community. (p. e98)

Paige and Daley (2009) identify three key components of situated cognition necessary for learning to take place in context: "people,"“ingredients," and "activity"(2009, p. e99). Our use of situated peer coaching during scripted unfolding case studies utilizes all three components to situate the learning of fundamental nursing skills in the context of a realistic healthcare scenario.

\section{USE OF SITUATED PEER COACHING WITH SCRIPTED UNFOLDING CASE STUDIES IN THE FUNDAMENTALS SKILLS LABORATORY}

In a typical laboratory session instructors briefly demonstrate the new skills for the day. Student practice is embedded in scripted simulation scenarios that follow. We created unfolding case studies for four imaginary patients. Each patient has a chart including a history and physical, progress notes, nurse's notes, and test results. Each week as the case unfolds, more information about the patient is revealed. Peer coaches use a script to provide instruction and realism as their partner cares for one of these patients in a 15- to 45-minute simulated scenario.

The peer coach guides the student partner through the scenario and acts as the voice of the patient. The student who plays the role of the nurse practices psychomotor skills, utilizes communication skills, and solves problems as the case unfolds. In these situated learning scenarios students learn to read prescribers' orders and test results, complete a focused assessment, and utilize SBAR (Situation, Background, Assessment, and Recommendation) communication techniques (Thomas, Bertram, \& Johnson, 2009) to communicate with other healthcare providers. Students must provide for safety and infection control during every encounter. To help prevent skill decay, previously learned skills are 
woven into each scenario. Throughout the scenario the peer coach is able to provide the other student with immediate formative feedback. The script provides the coach with information about what to watch for and how to prompt and guide the fellow student through the situation. After one scenario is completed, the roles are switched and the other student provides care for a different patient. Laboratory instructors are in the room observing, answering questions, and providing formative feedback as the student dyads work through their scenarios.

At the end of each scenario the coach reads a debriefing exercise: a guided reflective discussion of the encounter. Both the peer coach and the student who provided nursing care share their thoughts. The student who provided nursing care documents the scenario. Documentation must include not only the new skill performed (e.g. sterile dressing change, colostomy care etc.) but also teaching, patient safety, patient outcomes, and any communication with the provider. Telephone orders are written and read back.

An important key to the success of these scenarios is adequate preparation. Students are given instructions on coaching at the beginning of the semester where they are taught to allow their colleagues time to think before providing prompts and are encouraged to ad-lib in patient interactions. Prior to each laboratory, students prepare by completing reading assignments, attending a lecture that covers the theory behind the skills they will be performing, viewing skills videos, and taking an open-book group quiz. Students are not provided with the scripts of the scenarios they will be encountering as the nurse so that the situation truly is presented as an unfolding case.

Through scripted unfolding case studies students practice using the knowledge, skills, and attitudes (QSEN, n.d.) necessary to provide safe, highquality nursing care, and these are reinforced with every practice session. Immediate formative feedback is provided by peer coaches and additional feedback may be provided by instructors in the room during these scenarios. Summative evaluation of students' ability to provide safe, patient-centered care, and collaborate with other health professionals are provided during laboratory pass-offs when instructors assess students in a one-on-one setting.

\section{PURPOSE AND RESEARCH QUESTIONS}

The aim of this study was to measure the impact of situated peer coaching of unfolding case studies on student satisfaction, perceptions of learning, and selfevaluations in the Fundamentals Skills Laboratory. 
Himes and Ravert: Situated Peer Coaching and Unfolding Cases in Fundamental Lab

The following research questions were addressed:

1. Will student ratings of the Fundamentals Skills Laboratory change after implementing situated peer coaching with scripted unfolding case studies?

2. How do students' self-evaluations change over time and across laboratories when implementing situated peer coaching with scripted unfolding case studies in the Fundamentals Skills Laboratory?

3. What are the students' reactions to situated peer coaching with scripted unfolding case studies in the Fundamentals Skills Laboratory?

\section{METHODS}

\section{Recruitment and Participants}

A pilot study was conducted to test the measures and the procedures for one academic semester. Based on pilot results, we modified the instrument so that "exceeds expectations" with a numeric rating of five was placed on the right side of the paper form and "below expectations" with a numeric rating of zero is on the left. We also modified some of the scripts for the unfolding case studies to enhance student understanding. Approval was then obtained from the Institutional Review Board of a large private university in the U.S. to complete this formal study, which took place over two academic semesters. Participation was voluntary and students received no reward for taking part in the study. Students who consented to participate in this study were in their first year of the nursing curriculum in a baccalaureate program.

\section{Study Design}

This is a mixed methods study. The first question was approached using a quasi-experimental design with no control group and both pre- and postintervention data. The second question was approached with a quasi-experimental repeated measures quantitative design with no control group. To answer the third question, we used a qualitative approach in evaluating students' comments following each laboratory.

\section{Instruments}

The University Student Ratings tool has been used widely at the university for many years. Content validity for this instrument is supported; it was developed by instructional design experts and is based on best practice in teaching and learning. The assessment asks students to rate their courses and instructors and is administered anonymously via the internet at the end of each semester. For this study we chose to utilize five of the instrument's measures that aligned most with 
our study objectives: overall course, amount learned, effectiveness of materials and activities, active student involvement, and effectiveness of concept explanations.

The Simulation Evaluation tool was developed by T.F. Cicero and A.W. Mikasa at Seattle University(Personal Communication, Cicero \& Mikasa, June 2008; cicero@seattleu.edu or mikasaa@seattleu.edu). This instrument was designed for either instructors or students to evaluate performance in five key areas:

1. assessment, intervention, evaluation

2. critical thinking, clinical decision making

3. direct patient care

4. communication, collaboration

5. professional behaviors

Students rate themselves on a 6-point Likert scale ranging from a score of $0-5$ with " 0 " representing "below expectations" and " 5 " representing "exceeds expectations." Each area has a list of statements to explain what performance at a given level might look like. The instrument includes blank space at the end of the scale with the prompt "comments," where students give feedback about the laboratory and share thoughts about their experiences. Content validity for this instrument is supported; simulation experts developed it based on simulation best practice.

\section{Data Collection and Analysis}

Immediately following each laboratory, students completed the Simulation Evaluation tool to rate their own performance in five areas and provide written comments if desired. At the end of each semester the University Student Ratings were completed. Quantitative analyses were done using PASW Statistics 18 software. An alpha of .05 was used for statistical significance. For research question one an ANCOVA was run to test the difference between the old method and the new method of teaching for each of the five University Student Ratings' measures while controlling for the rating of the instructor. We compared the ratings from two semesters prior to implementing the new method to the first two semesters in which the new method was fully implemented. For research question two, a repeated measures ANOVA was conducted to determine how students' self-ratings using the Simulation Evaluation tool changed across time.

To answer the research question three we used thematic analysis of the students' written comments on the Simulation Evaluation tool. Coding began as 
Himes and Ravert: Situated Peer Coaching and Unfolding Cases in Fundamental Lab

data were collected. The primary investigator and research assistants met weekly to review and evaluate the data, codes, and themes. In vivo coding and open coding were used to identify significant experiences and feelings and develop initial categories. Member checking and axial coding followed to clarify the data and refine themes.

\section{FINDINGS}

The sample included 104 students who were predominantly Caucasian $(n=97,93 \%)$, females $(n=96,92 \%)$, and ranged in age from 19 to 37 years with a mean of $20.7(S D=2.37)$. Their average GPA was $3.78(S D=0.12)$. Just over half of the participants were employed at the time of the study, with $16.3 \%$ of the total sample working in healthcare related positions. The participation rate was $96.3 \%$. Four students declined.

Research Question \#1: Will student ratings of the Fundamentals Skills Laboratory change after implementing situated peer coaching with scripted unfolding case studies?

While controlling for the covariate of instructor rating, ANCOVA yielded no statistically significant differences $(p>.05)$ in student ratings of the laboratory when comparing student responses prior to implementation of the new teaching method with responses after implementation. Student ratings remained high in each category. With this instrument, students rate statements about the course on an 8 point scale from $1=$ very strongly disagree, to $8=$ very strongly agree; or $1=$ exceptionally poor, to 8 = exceptionally good.

Table 1.Means and Standard Deviations for Student Ratings of Course Pre- and PostImplementation of Situated Peer Coaching and Unfolding Case Studies

\begin{tabular}{lll}
\hline Dependent Variable & $\begin{array}{l}\text { Old Method } \\
\text { Mean }(\boldsymbol{S D})\end{array}$ & $\begin{array}{l}\text { Peer Coaching Method } \\
\text { Mean }(\text { SD) }\end{array}$ \\
\hline Active Student Involvement & $7.39(.81)$ & $7.39(.67)$ \\
Amount Learned & $7.44(.68)$ & $7.54(.60)$ \\
Explained Concepts Effectively & $7.16(.89)$ & $7.02(.77)$ \\
Materials \& Activities Effective & $7.42(.75)$ & $7.42(.65)$ \\
Overall Course & $7.23(.70)$ & $7.26(.64)$ \\
\hline
\end{tabular}

Research Question \#2: How do students' self-evaluations change over time and across laboratories when implementing situated peer coaching with scripted unfolding case studies in the Fundamentals Skills Laboratory? 
A one-way within-subjects ANOVA was conducted with the factor being the laboratory number and the dependent variable being the summed scores on the students' self-assessments using the Simulation Evaluation tool. The results showed a significant time effect, indicating that students tended to rate themselves higher in all areas as the semester progressed. Wilk's $\Lambda=.180, F(8,65)=36.92$, $p<.000$. Follow-up polynomial contrasts indicated a significant linear effect with means that generally tended to hold steady or increase slightly over time, $F(1,72)$ $=11.85, p<.001$. The exception to this slight increase was laboratory number four, which is the first laboratory in which students administer injections. In the fourth laboratory, students perceived their overall performance as higher than any of the other laboratories. Table 2 displays composite means and standard deviations for the student self-ratings by laboratory.

Previous reliability data for the Simulation Evaluation tool have not been published. In this study the Cronbach's alpha statistic was assessed for each laboratory. Alphas ranged from .809 - .924 indicating high internal consistency. The reliability of this instrument would not improve if any single item on the instrument were deleted.

Table 2. Means and SD for Composite Self-Evaluation Scores

\begin{tabular}{lll}
\hline Laboratory Number \& Title & $\boldsymbol{M}$ & $\boldsymbol{S D}$ \\
\hline Hygiene & 16.78 & 3.09 \\
Mobility & 18.05 & 3.20 \\
Oxygenation & 17.27 & 2.99 \\
Med Laboratory \#1 ** & 23.30 & 3.61 \\
Med Laboratory \#2** & 18.49 & 3.30 \\
Med Laboratory \#3 & 19.33 & 3.27 \\
Wound Care & 19.12 & 3.19 \\
Urinary & 19.23 & 3.30 \\
Bowel & 18.71 & 2.95 \\
\hline
\end{tabular}

**Situated peer coaching and unfolding case studies not implemented

Research Question \#3: What are the students' reactions to situated peer coaching with scripted unfolding case studies in the Fundamentals Skills Laboratory? 
Himes and Ravert: Situated Peer Coaching and Unfolding Cases in Fundamental Lab

All comments were read by research team members familiar with the course and student performance. Major themes identified from student comments include (a) student preparation, (b) communicating with the "patient", (c) working with situated peer coaching, (d) critical thinking, and (e) learning through scenarios. See Table 3 for a summary of themes and sub-themes.

Table 3. Themes Related to Participants' Perception of Situated Peer Coaching with Unfolding Case Studies

\begin{tabular}{ll}
\hline Themes & Sub-Themes \\
\hline \multirow{3}{*}{ Student Preparation } & Identification of preparation activities that helped \\
& Need for preparation to be able to perform \\
Communication with the & Finding the right words to communicate with patients \\
"Patient" & Reacting/responding to patient needs and comments \\
& Multi-tasking(teaching/communicating while working) \\
Working with Situated Peer & Friendly learning environment \\
Coaching & Feedback in real time \\
& Peer coaches learn when playing the patient role \\
& Need to help the coaches learn their role \\
Critical Thinking & Apply knowledge (facts) to problem solve \\
& Building critical thinking skills is necessary \\
Learning Through Scenarios & Need to consider many things at once (safety) \\
& Solidifies learning - I will remember \\
& Realistic - variation among patients \\
\end{tabular}

Student Preparation. Students frequently commented on whether or not they felt prepared for the unfolding cases simulated in the laboratory. Comments focused on which types of preparation (reading, quiz, skills videos, and previewing the scenario) were helpful, and what they could do to better prepare in the future. For example:

I felt more prepared this time because I watched all videos and did all the reading. I didn't read one of the scenarios [orders] closely enough and didn't realize Etsuko would be NPO, so I can do better at this next time. (Mobility Laboratory)

Early on in the semester many students realized that laboratory is intended to provide an environment where they can apply their knowledge and challenge their critical thinking skills. They realized it takes a different mindset to prepare for performance. One student wrote at the end of the first laboratory: 
I didn't watch the videos so I wasn't as prepared as I should have been. I'll make better effort in this area so next week will be a better experience. (Hygiene Laboratory)

Communication. While working through the scripted scenarios, students were required to communicate with their patients, and several commented it was sometimes difficult to find the right words to use.In one situation the fictional patient [Rhonda Flinders] has just returned from surgery. The surgery results in an unexpected colostomy and although the surgeon did speak with her following the procedure, she was still under the effects of anesthesia and can't remember that she had a colostomy placed. When the student checks the colostomy, the bag has fallen off and the student has to replace it. This gives the student the opportunity to practice delivering bad news. By this point in the semester the students have had this content in class, but never had an opportunity to practice it. The peer coach watches and uses the script to prompt the student nurse as needed through a difficult conversation. A couple of students' comments:

I think it was hard to deliver bad news. I would definitely put more thought into it beforehand. (Bowel Laboratory)

I am still stumbling over how to say things to patients. I know what they need to be told, I just have a problem stating it in a way that isn't offensive and is understandable. I am sure this will come with practice. (Mobility Laboratory)

Students also noted that communicating during the scenarios requires them to react and respond to real patient needs. During another scenario a fictional patient [Thomas Edwards] has pneumonia, dehydration, and constipation. The peer coach follows the script and in the patient voice reports that his stools are quite hard at times and that sometimes he has to "dig them out with my finger." Students have learned about digital removal of stool. They understand that patients might need to be questioned directly to report such practices. However, they are often taken by surprise and do not know how to react when these situations come up. One student said:

\section{Communication was hard because some of the comments are shocking.}

During the debriefing students are asked questions such as, "How did you react to hearing that Mr. Edwards needs to perform digital removal of his stool at times?" and "Do you think that your reaction was one that will encourage him to share sensitive health history with medical professionals in the future?" 
Himes and Ravert: Situated Peer Coaching and Unfolding Cases in Fundamental Lab

A primary focus of scenarios is to help students learn to talk with their patients and teach them while performing tasks. Students recognized this important skill will take practice:

I wasn't very good at communicating with the patient because I was too concerned with my sterile technique. (Urinary Laboratory)

Working with Situated Peer Coaching. Students commented on their experiences working with situated peer coaching. Some students noted that it would be helpful if the coaches could view the scripts prior to the laboratory. Others commented on a related need to train the coaches better for their role. One student noted:

I think it would be helpful to go over a few of the coach pointers before. My partner didn't pass on all the info. (Oxygenation Laboratory)

Other students commented on how helpful it was to work in pairs, noting that it is a good learning environment and the instant feedback is helpful:

I really like having a peer be the coach. It is less intimidating and a friendly learning environment where we can drill and question someone who is eager to learn it with you. (Hygiene Laboratory)

Other students noted they learned when they were in the coach role as well as when in the nurse role. As the coach, they also played the role of the patient. This was beneficial:

Acting as the patient gave me insights into how to be a better nurse (Mobility Laboratory)

Critical Thinking. Students observed there is a difference between gaining knowledge and being able to apply knowledge. They commented that reading a list of symptoms in a book is not the same as being presented with a few of those symptoms and trying to figure out what is wrong with the patient and how to react. In one scenario a patient [Etsuko Moriyama] develops a pulmonary embolus. The students are not told the diagnosis, and the symptoms unfold over time. Students had to use their knowledge to problem solve. One student commented:

I'm really glad we had this lab, I wouldn't learn about when I need to take action and call the doctor by just reading - it helps to do it! (Oxygenation Laboratory) 
Students recognized that activities like this are important to build necessary critical thinking skills:

This lab was really beneficial to see how something could go wrong really fast. It showed me that I need to be [a] little more prepared and work on my critical thinking skills. It taught me a lot about relating signs and symptoms to many different diagnoses. I've got to think about the serious consequences too. (Oxygenation Laboratory)

Learning Through Scenarios. Students talked about what it was like to work with unfolding case studies with a peer coach acting as the patient and giving feedback. Scenarios provide the opportunity to take a full patient picture into account. Students recognized they need to consider many things at once including safety and infection control issues. If needed, coaches are instructed to prompt with questions like, "Do we need to consider anything before rolling the patient?'One student commented:

I could work on better communication with the patient and also safety. I didn't remember about the guard rails and [patient] position and hand sanitizer. (Hygiene Laboratory)

Students identified learning through scenarios as an activity that helps solidify learning and remember important nursing actions to the point that they become automatic:

I think role-playing will be really good in helping me make good habits and cement the skills that I read about. (Hygiene Laboratory) is different:

They noted that these scenarios reflect the "real world" where each patient

I think the scenarios are very useful because not every patient we care for will be exactly the same with the stereotypical textbook scenarios. (Hygiene Laboratory)

By the end of the semester the students had gained an appreciation for this type of learning:

I was amazed at my ability to collect information and remember everything I needed to without too much effort. The labs have been awesome to prepare me for becoming a nurse. I feel like I have learned so much through hands-on laboratory experience.(Final Pass-off) 
Himes and Ravert: Situated Peer Coaching and Unfolding Cases in Fundamental Lab

[This was an] atmosphere where we can learn and retain that information. (Final Pass-off)

\section{DISCUSSION}

This study explored students' responses to the implementation of situated peer coaching and unfolding case studies in the Fundamentals Skills Laboratory. Student responses were assessed by examining (a) the student ratings both preand post- implementation, (b) students' self-evaluations using the Simulation Evaluation tool, and (c) student comments following each laboratory. All measures indicated a positive student response to the teaching method.

\section{Student Ratings}

Students rated this course as "exceptionally good" with averages above 7 points on an 8 point scale both prior to and after implementing situated peer coaching (see Table 1). We had hoped to see a statistically significant increase in some of the course ratings; however, ratings were so high initially that it would be difficult to increase significantly.

\section{Student Self-Evaluations}

As measured by the Simulation Evaluation tool, students' self-assessments of performance were high and slightly rose over the course of the semester. The exception to this was the fourth laboratory, where there was a significant increase in students' self-ratings. This finding was surprising to the investigators. In this laboratory students administer their first intramuscular injections. The fourth and fifth laboratories do not include unfolding case scenarios, but are preparatory to the sixth laboratory where a medication administration scenario occurs. It might be that the students' high self-ratings reflect their excitement to administer their first injections. Comments indicate that students "felt like a real nurse," and felt proud of their accomplishments on this day. The Simulation Evaluation tool was developed to measure performance in simulation. We would recommend against using this instrument when there is not a simulation component in a learning activity.

\section{Student Comments}

Student comments support what has been previously reported in the literature about peer learning. Ashgar (2010) reports that reciprocal peer coaching among same-level physical therapy students increases self-regulation and

motivation. In the present study, students indicated a strong desire to come 
prepared to laboratory so they would be able to perform well during their scenarios. Students commented frequently on perceptions about their own critical thinking and their application of safety principles. This finding supports the assertion by Liu and Carless (2006) that formative peer assessment can enhance students' ability to self-assess. In this study students reported that situated peer coaching is a "friendly learning environment" and they were comfortable with both giving and receiving formative feedback from peers. Similar results have been seen with other forms of peer-learning in the Fundamentals Skills Laboratory such as peer teaching where more advanced students teach skills to junior students (Goldsmith, et al., 2006); however, this is the first study to report on same-level peers coaching one another through scripted scenarios in the Fundamentals Skills Laboratory.

Scripted unfolding case studies create opportunities for students to face real world situations where nurses deal with multiple priorities and time pressures while providing interactive patient care. We found that situated peer coaching can provide students the opportunity to learn and practice more than psychomotor skills in the Fundamentals Skills Laboratory; through this instructional strategy students can practice and learn nursing roles and attitudes.

\section{LIMITATIONS AND DIRECTIONS FOR FUTURE STUDY}

One limitation to this study is lack of a control group. A similar study with a crossover control group would help describe differences between instructor demonstration followed by situated peer coaching and instructor demonstration followed by student practice that is not situated in context. It is unknown to what degree this instructional strategy impacts student performance in the clinical setting. Future studies should attempt to describe the impact of situated peer coaching in the skills laboratory on clinical performance.

\section{CONCLUSION}

Situated peer coaching through scripted unfolding case studies in the Fundamentals Skills Laboratory provides contextualized learning and individual feedback for students. Students rated themselves highly and evaluated the course highly when participating in this method of learning. By modifying our Fundamentals Skills Laboratory to incorporate situated peer coaching we have been able to teach much more than task-based psychomotor skills. Students are now engaged in situated cognition (Benner, et al., 2010); as they perform psychomotor skills they are also focusing on nursing roles, values, and judgments. 
Himes and Ravert: Situated Peer Coaching and Unfolding Cases in Fundamental Lab

\section{REFERENCES}

Asghar, A. (2010). Reciprocal peer coaching and its use as a formative assessment strategy for first-year students. Assessment \& Evaluation in Higher Education, 35(4), 403-417. doi: 10.1080/02602930902862834

Azzarello, J., \& Wood, D. E. (2006). Assessing dynamic mental models: Unfolding case studies. Nurse Educator, 31(1), 10-14. doi: 00006223200601000-00004

Bamber, M., Graven, L., Abendroth, M., Park, H., Grubbs, L., \& Plowfield, L. (2010). Embedding an unfolding geriatric case exemplar into nursing simulation. Clinical Simulation in Nursing, 6(3), e108. doi: 10.1016/j.ecns.2010.03.009

Benner, P., Sutphen, M., Leonard, V., \& Day, L. (2010). Educating nurses: A call for radical transformation. San Fransisco, CA: Jossey-Bass.

Bensfield, L., Solari-Tiwadell, P. A., \& Sommer, S. (2008). The use of peer leadership to teach fundamental nursing skills. Nurse Educator 33(4), 155158.

Chojecki, P., Lamarre, J., Buck, M., St-Sauveur, I., Eldaoud, N., \& Purden, M. (2010). Perceptions of a peer learning approach to pediatric clinical education. International Journal of Nursing Education Scholarship, 7(1), $1 \mathrm{p}, 1-14$.

Day, L. (2011). Using unfolding case studies in a subject-centered classroom. Journal of Nursing Education, 50(8), 447-452.

Evans, D. J., \& Cuffe, T. (2009). Near-peer teaching in anatomy: An approach for deeper learning. Anatomical Sciences Education, 2(5), 227-233. doi: $10.1002 /$ ase. 110

Godson, N. R., Wilson, A., \& Goodman, M. (2007). Evaluating student nurse learning in the clinical skills laboratory. British Journal of Nursing, 16(15), 942-945.

Goldsmith, M., Stewart, L., \& Ferguson, L. (2006). Peer learning partnership: An innovative strategy to enhance skill acquisition in nursing students. Nurse Education Today, 26(2), 123-130. doi: DOI 10.1016/j.nedt.2005.08.001

Harlow, L. L., Burkholder, G. J., \& Morrow, J. A. (2006). Engaging students in learning: An application with quantitative psychology. Teaching of Psychology, 33(4), 5p. doi: 10.1207/s15328023top3304_3

Hunt, C. W., \& Ellison, K. J. (2010). Enhancing faculty resources through peer mentoring. $\quad$ Nurse Educator, 35(5), 192-196. doi: 10.1097/NNE.0b013e3181ed8143

Institute of Medicine of the National Academies (IOM). (2010). The future of nursing: Focus on education report brief. Washington, DC: The National Academies Press. 
Iwasiw, C. L., \& Goldenberg, D. (1993). Peer teaching among nursing students in the clinical area: Effects on student learning. Journal of Advanced Nursing, 18(4), 659-668.

Ladyshewsky, R. K. (2000). Peer-assisted learning in clinical education: A review of terms and learning principles. Journal of Physical therapy Education, 14(2), 15-22.

Ladyshewsky, R. K. (2010). Building competency in the novice allied health professional through peer coaching. Journal of Allied Health, 39(2), e-77e-82.

Liu, N., \& Carless, D. (2006). Peer feedback: The learning element of peer assessment. Teaching in Higher Education, 11(3), 279-290.

Oermann, M. H., \& Gaberson, K. B. (2009). Evaluation and Testing in Nursing Education (third ed.). New York: Springer.

Owens, L. D., \& Walden, D. J. (2001). Peer instruction in the learning laboratory: A strategy to decrease student anxiety. Journal of Nursing Education, 40(8), 375-377.

Page, J. B., Kowlowitz, V., \& Alden, K. R. (2010). Development of a scripted unfolding case study focusing on delirium in older adults. Journal of Continuing Education in Nursing, 41(5), 225-230. doi: 10.3928/00220124-20100423-05

Paige, J. B., \& Daley, B. J. (2009). Situated cognition: A learning framework to support and guide high-fidelity simulation. Clinical Simulation in Nursing, 5(3), e97-103.

Poe, S. S., Abbott, P., \& Pronovost, P. (2011). Building nursing intellectual capital for safe use of information technology: A before-after study to test an evidence-based peer coach intervention. Journal of Nursing Care Quality, 26(2), 110-119. doi: 10.1097/NCQ.0b013e31820b221d

QSEN. (n.d.). Quality and safety education for nurses. Retrieved 5/14/2012, from qsen.org

Reese, C. E. (2011). Unfolding case studies. Journal of Continuing Education in Nursing, 42(8), 344-345. doi: 10.3928/00220124-20110722-04

Secomb, J. (2008). A systematic review of peer teaching and learning in clinical education. Journal of Clinical Nursing, 17(6), 703-716.

Sprengel, A. D., \& Job, L. (2004). Reducing student anxiety by using clinical peer mentoring with beginning nursing students. Nurse Educator, 29(6), 246250. doi: 00006223-200411000-00010

Topping, K. J. (2005). Trends in peer learning. Educational Psychology, 25(6), 631-645.

Waddell, D. L., \& Dunn, N. (2005). Peer coaching: The next step in staff development. Journal of Continuing Education in Nursing, 36(2), 84-89; quiz 90-81. 
Himes and Ravert: Situated Peer Coaching and Unfolding Cases in Fundamental Lab

Wilkins, E. A., Shin, E., \& Ainsworth, J. (2009). The effects of peer feedback practices with elementary education teacher candidates. Teacher Education Quarterly, 36(2), 79-93.

Zadvinskis, I., Glasgow, G., \& Salsbury, S. (2011). Developing unit-focused peer coaches for the clinical setting. Journal of Continuing Education in Nursing, 42(6), 260-269. doi: 10.3928/00220124-20110215-02 